\title{
The Influence of IT on Women's Entrepreneurial Intention in the Saudi Context
}

\section{Asma Aleidi}

School of Information, Systems and Modelling

University of Technology Sydney;

Princess Nourah bint Abdulrahman University

Email: asma.i.aleidi@student.uts.edu.au

\section{Daniel Chandran}

School of Information, Systems and Modelling

University of Technology Sydney

Email: Daniel.Chandran@uts.edu.au

\section{Abstract}

IT entrepreneurship is becoming an increasingly vital source for promoting socio-economic growth, innovation and job opportunities. Despite the increasing awareness of this importance, evidence indicates that women participation in entrepreneurship with a particular focus on technological entrepreneurship remains low. Furthermore, there has been minimal research about female entrepreneurship from a technological point of view. Our goal in this study is to propose a model that extends the theory of planned behavior by incorporating the technological factors into established entrepreneurial models. Investigating such factors is beneficial for motivating a new generation of women entrepreneurs in the IT context. In addition, it helps to provide a further understanding to IS researchers and practitioners.

Keywords IT Entrepreneurship, Female Entrepreneurship, Entrepreneurial Intentions, Innovation, Saudi Arabia 


\section{Introduction}

Entrepreneurial business and small ventures contribute to economic growth and innovation. More specific, we could observe an increasing awareness of the importance of IT entrepreneurship and innovation (Aleidi and Chandran 2017b; Chen 2013; Chen 2014; Dutta et al. 2015). However, recent studies indicate that despite the growing attainment within the engineering and technology (SET) sector, women entrepreneurs are heavily underrepresented (Chandran and Aleidi 2018; Ezzedeen and Zikic 2012; Hampton et al. 2011; Marlow and McAdam 2012). In particular, female entrepreneurship from the IT perspective is in its infancy. In spite of this indication, there is little research in this area. Consequently, as technological entrepreneurship continues to grow, and given the lack of women's IT entrepreneurial activities there is a need for further investigation. In particular, in order to encourage women tech-entrepreneurs, there is a need for identifying and understanding the factors and decisionmaking processes that affect women's engagement in such businesses. As Saudi government in particular has recently commenced various initiatives in an effort to support entrepreneurial leadership among Saudi youth, and enhance women's role in the labor force and economic sector through entrepreneurship leadership, it is essential to understand what influences individual's specific intention to engage in innovation and technological entrepreneurship. This understanding would also help to support and empower women's progress as entrepreneurs, and ultimately benefit our society through increased the culture of entrepreneurship, economic activity, innovation and creation of jobs. Moreover, this understanding could help to motivate new female generation for technological entrepreneurship as an attractive career. As has been argued by Almobaireek, and Manolova (2013), in contrast to findings from studies on entrepreneurial motivations in the context of Western Europe and the USA, young Saudi university women report a narrower range of entrepreneurial motivations, compared to men. Finally, for those women who have already entered the ranks of IT-related business founders, it is also important to develop an understanding of them to achieve successful and sustainable IT entrepreneurship and innovation. Our research contributes to this emerging body of work by aiming to answer the following research questions:

- What role do attitude, entrepreneurial self-efficacy, and subjective norms play in the explanation of women's IT entrepreneurial intention?

- How do technological factors affect women's IT entrepreneurial intention?

We position these constructs by drawing upon the theory of planned behavior (TPB) and the literature on IS and female entrepreneurship to establish a model of women's IT entrepreneurial intention to understand the phenomenon in which little is yet known such as female IT entrepreneurial behavior in developing countries such as Saudi Arabia. Understanding what influences an individual's specific intention to engage in innovation and technological entrepreneurship; better guidance can be a new driver of IT entrepreneurial behavior to a disadvantaged population with high economic potential such as women in the Saudi context.

\section{Literature Review}

\subsection{IT Entrepreneurship Space}

In recent years, technological entrepreneurship has been one of the most important drivers of economic growth, social value, and innovation (Chen 2013; Chen 2014; Dutta et al. 2015; Marvel and Lumpkin 2007; Willie $\mathrm{O}$ et al. 2011). As a starting point, technological entrepreneurship, also referred to as technology-based entrepreneurship is defined as the setting up of new firms by individuals or corporations to exploit technological innovation (Willie $\mathrm{O}$ et al. 2011). The dominant perspective on technological entrepreneurship views it as a relationship of enterprising individuals and systems of innovation. In this perspective, Autio (1997) define a new technological entrepreneurship as a firm with highly technology intensive, which is based on the exploitation of technological knowledge and capability (Autio 1997). Chen (2013; 2014) shows that the industry of IT is one of the most important and influential businesses, which rapidly incubate entrepreneurs. Such businesses have played an enormous role by creating entire new industries such as the computer industry, software industry, and Internet industry (Chen 2013, 2014).

IT entrepreneurs are understood as individuals, who organize, manage and accept the risk of IT entrepreneurship (Chandran and Aleidi 2018; Nichols and Armstrong 2003). Studies indicate that IT entrepreneurs have distinctive behavioral characteristics and different antecedents' factors, which are highly related to technical skills and perceptions (Aleidi and Chandran 2017a; Chen 2013; Chen 2014; Dutta et al. 2015). They are expected to have more technical related knowledge in addition to higher 
innovation capabilities and attitudes. For instance, Marvel and Lumpkin (2007) found that formal education and prior knowledge of IT are important determents to innovation outcomes of technology entrepreneurs (Marvel and Lumpkin 2007). Similarity, Chen (2014), prove that computer self-efficacy and personal innovativeness with IT significantly explain intention to start up an IT-related business. Furthermore, Dutta et al. (2015) show that personal innovativeness in IT and related knowledge and experience of the IT entrepreneur act as key drivers.

\subsection{Women Entrepreneurs in Saudi Arabia}

In recent years, Saudi Arabia has witnessed strong growth in entrepreneurship in general and more specifically in female entrepreneurship. Although, women are traditionally restricted to join the economic field for a long time (Almobaireek and Manolova 2013), there is a quantum leap of women status in this area, driven largely by changing the direction of the Saudi government to support women's empowerment and gender equality (Aleidi and Chandran 2017a; Chandran and Aleidi 2018). According to Global Entrepreneurship Monitor 2016, the male rate of participation in the early-stage entrepreneurial activity (TEA) is $12.9 \%$ and the female rate $9.7 \%$ in the Saudi context. Although participation in TEA has been increasing across both genders, women have been rapidly closing the gap since 2009 (Roomi et al. 2017). The Saudi government has launched many entrepreneurship initiatives in an effort to support the entrepreneurial culture, develop entrepreneurial leadership among Saudi youth, and enhance women's role in the labor force and economic sector through entrepreneurship leadership. For example but not limited to, Aramco Entrepreneurship Center, and Badir Program from the scientific organization of King Abdulaziz City for Science and Technology (Chandran and Aleidi 2018). More recently, Vision 2030, which is a recent policy view of Saudi government marks a new phase in the development by promoting and supporting Small and Medium Enterprises (SMEs) to create suitable job opportunities for Saudi citizens as well as increasing women's participation in the workforce (Chandran and Aleidi 2018). It aims to support the Kingdom's sustainable development in the light of global trends that focus on technology, and innovation in the knowledge-based economy. in this regard, Misk, which is inspired by the vision, provides a variety of fellowship and traineeship programs for women to support the government's efforts in achieving the Kingdom's Vision 2030, which encompasses the improvement of women's participation as well as capacity building and empowerment in order to increase their contribution to the development (Misk 2018).

\section{Research Model and Hypotheses Development}

The primary research goal is to conceptualize a women's IT entrepreneurial intentions model based on relevant research and current empirical studies to investigate the factors that affect women's IT entrepreneurial intention in the Saudi context. Two major streams of literature provide the theoretical foundations for this research. First, the literature on entrepreneurial behaviour, illustrating the role of intention as well as its antecedents including attitude toward entrepreneurship, entrepreneurial selfefficacy, and subjective norms. Second, the literature on information systems (IS), elaborating the role and importance of three context-specific factors computer self-efficacy, personal innovativeness in IT, and related knowledge and experience in technology as key drivers of entrepreneurial intention in technological entrepreneurship.

\subsection{Theory of Planned Behavior}

A considerable amount of literature argues that intention plays a relevant role in decision making to start a new firm and predict entrepreneurial behavior (Díaz-García and Jiménez-Moreno 2010; Krueger et al. 2000). Theory of planned behaviour (TPB) by Ajzen (1991) is a broad theory of human behavior, which has been successfully adopted to predict and explain intentions to perform behaviors (Ajzen 1991; Autio et al. 2001). Ajzen's theory has also become the most influential and increasingly common framework in entrepreneurial intention literature (Autio et al. 2001; Díaz-García and Jiménez-Moreno 2010; Krueger et al. 2000) among others. According to the TPB, entrepreneurial intention illustrates the effort that is required from individuals to acquire the entrepreneurial behavior (Krueger et al. 2000). And so, it is considered to be influenced by three antecedents. First, individual's attitude, subjective norms, and the degree of perceived behavioral control (Ajzen 1991; Díaz-García and Jiménez-Moreno 2010). The perception of behavioral control construct is similar to the construct of perceived self-efficacy (Díaz-García and Jiménez-Moreno 2010), which is adopted in this study. Both concepts reflect one's perceived ability to achieve a particular goal or behavior (Ajzen 1991; Anna et al. 2000). Utilizing intention- based model, Chen (2014) and Dutta et al, (2015) proposed models that identify important technological dimensions as key drivers of IT entrepreneurial intention, including computer selfefficacy, personal innovativeness with IT, and related knowledge and experience in IT. Figure 1 shows the research model. (More details are provided in the hypotheses development section). 


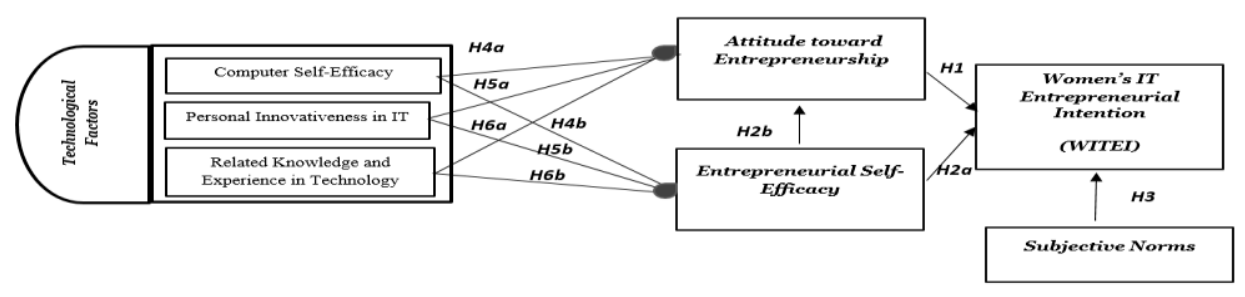

Figure 1: Research Model

\subsection{Hypotheses Development}

Attitude toward entrepreneurship refers to the degree to which an individual has a positive or negative personal evaluation about willingness to be an entrepreneur (Díaz-García and Jiménez-Moreno 2010). Higher positive attitude, greater the intention will be to perform a particular behavior including the entrepreneurial behavior (Autio et al. 2001; Chandran and Aleidi 2018; Díaz-García and JiménezMoreno 2010) among others. Attitudes influence the development of women entrepreneurial intention and assessed as inside dimensions of the individual to perform the actual behaviour. Accordingly, the following hypothesis is proposed

H1: Attitude towards entrepreneurship influences positively women's IT entrepreneurial intention.

Entrepreneurial self-efficacy (ESE) reflects an individual's perceived capability to perform entrepreneurial roles successfully (Chen et al. 1998). Many studies suggest that individual's with higher entrepreneurial self-efficacy has higher entrepreneurial intentions (Chen et al. 1998; Krueger et al. 2000). However, the literature shows that, compared to men, women tend to perceive themselves and the entrepreneurial environment less desirable (Langowitz and Minniti 2007). This perception in turn influences their self efficacy, intentions and subsequent lower levels of entrepreneurial behavior (Wilson et al. 2007; Zhao et al. 2005). Additionally, there is evidence that women are more likely than men to limit their career choice and interests due to their low perception of the necessary skills (Aleidi and Chandran 2018; Wilson et al. 2007). Palmer et al. (2015) find that the relationship between gender and entrepreneurial intentions was reduced when self-efficacy was considered (Palmer et al. 2015). Therefore, it is important to consider that women perceptions of themselves play a greater role in the decision to start a business. Furthermore, women who exhibited higher beliefs regarding their capabilities, their motivation and attitudes toward entrepreneurship will be stimulated and increased specifically when these women show a lower level of entrepreneurial attitude. This finding is consistent with Bandura (1986) indicating that self-efficacy causally influences expected outcomes of behavior, but not vice versa (Bandura 1986; Chen 2013). Whereas expected outcomes is linked to the attitude in Ajzen's TPB (Krueger et al. 2000). Accordingly, this study proposes the following hypotheses:

H2a: Entrepreneurial self-efficacy influences positively women's IT entrepreneurial intention.

H2b: Entrepreneurial self-efficacy influences positively attitude toward entrepreneurship.

The subjective norms construct is a social perception, which refers to perceived social pressure from people including family, friends and others to perform a certain behaviour (Ajzen 1991; DíazGarcía and Jiménez-Moreno 2010). A recent research has recognized that subjective norms have a great impact on entrepreneurial intention. The higher the perceived social pressure, the higher the IT entrepreneurial intention (Chandran and Aleidi 2018; Díaz-García and Jiménez-Moreno 2010). Therefore, we could observe that the environment and subjective norms play an important role in women's IT entrepreneurial intention. From IS perspective, this proposition is consistent with Venkatesh \& Morris (2000) assertion that women are strongly influenced by subjective norms perceptions of IT and IT usage intentions (Chandran and Aleidi 2018). Accordingly:

H3: Subjective norms influence positively women's IT entrepreneurial intention.

Computer self-efficacy (CSE) refers to the individual's belief in his/her capability to use computers in different situations (Compeau and Higgins 1995). Scholars demonstrate that CSE is a key component of an individual's behavior in using computers (Chen 2013; Chen 2014; Compeau and Higgins 1995; Venkatesh 2000). He and Freeman (2010a) illustrate that CSE beliefs can have an effect on behavioral intention through attitude (He and Freeman 2010). Furthermore, Chen (2013; 2014) demonstrated that CSE has a direct and positive impact on ESE, which in turn influences entrepreneurial intention. Consequently, it is reasonable to consider that CSE as an antecedent to attitude as well as entrepreneurial self-efficacy. CSE can be helpful increase the level of entrepreneurial attitude. It can 
help also to reduce the effects of low self-efficacy of women as previous studies show that compared to men, women more frequently have a reduced perception of their own entrepreneurial skills, regardless their real skills, particularly in sectors that are seen traditionally as male domains (Wilson et al. 2007). This is consistent with a finding that shows users who possess high CSE are more likely to form positive perceptions of IT and IT usage intentions (Venkatesh 2000). Based on the arguments explored above, the following hypotheses are proposed:

H4a: Computer self-efficacy positively influences women's attitude towards entrepreneurship.

H4b: Computer self-efficacy positively influences women's entrepreneurial self-efficacy.

Personal innovativeness in IT (PIIT): a considerable amount of IS literature has demonstrated that PIIT is associated with IT adoption and usage (Agarwal and Prasad 1998; Chen 2014; Dutta et al. 2015). PIIT represents "the willingness of an individual to try out any new information technology" (Agarwal and Prasad 1998, p. 3). From IS perspective, entrepreneurs highly depend on technological innovation to create new technology enterprises and new technologies (Chen 2014; Dutta et al. 2015). Some wellempirical studies have tested the relationship between PIIT and individual's behavior providing evidence of a significant relationship (Agarwal and Prasad 1998; Chen 2014; Dutta et al. 2015). Furthermore, it is also reasonable to expect that PIIT could play a critical role in the development of the poor attitude toward IT entrepreneurship as well as the increasing of entrepreneurial self-efficacy. This proposition confirms previous studies showing that individual with high PIIT will improve his/her ability, motivate him/her to incubate technological innovation and look for ways it could be deployed to transform technology innovation into market opportunity (Dutta et al. 2015). Thus, the following hypotheses are proposed:

H5a: Personal innovativeness in IT positively influences women's attitude towards entrepreneurship.

H5b: Personal innovativeness in IT positively influences women's entrepreneurial self-efficacy.

Related knowledge and experience (RKE) play a critical role with regarding the development of IT entrepreneurial intention. Computer knowledge refers to the self-perception of the extent of knowledge regarding the use of computers across different application domains. A prior computing experience is defined as the frequency of using computers across different tasks and purposes. Both factors reflect an individual's direct experience with computers from the past and the present (He and Freeman 2010). Individuals with a high level of RKE will enable them to connect the previous relevant knowledge with the new knowledge, which in turn helps to identify and develop opportunities at the intersection (Dutta et al. 2015; Marvel and Lumpkin 2007). Furthermore, assimilation of new knowledge and technologies such as software process innovations is facilitated when individuals have greater related knowledge (Dutta et al. 2015; Fichman and Kemerer 1997; Lenox and King 2004). From these viewpoints, Dutta, et al, (2015) were able to demonstrate that RKE of the entrepreneur act as key drivers in virtual worlds' business, which positively influence the development of entrepreneurial self-efficacy and attitude. Therefore, the following hypotheses are developed:

H6a: Related knowledge and experience positively influence women's attitude towards entrepreneurship.

H6b: Related knowledge and experience positively influence women's entrepreneurial self-efficacy.

\section{Research Method}

This study has used a quantitative method to collect numerical data from respondents. According to the literature, most studies of entrepreneurial intention have relied on student samples (Autio et al. 2001; Chen 2014; Díaz-García and Jiménez-Moreno 2010) among others. In this study, we surveyed a broad range of samples to increase the generalizability of undergraduate student populations to older, who would provide different levels of knowledge, experience, and perception. Hence, the sample consists of female university students in their last years, majoring in different disciplines including but not limited to students majoring in IT and other related areas as well as subjects related to business and management. Also, it includes female nascent entrepreneurs who are not entrepreneurs yet, but are pondering on it and in the process of starting a business (McGee et al. 2009). The data for the study was gathered based on an online survey of 475 responses from November 2017 until January 2018. With respect to the female university students, data has been collected in large, public universities in Saudi Arabia, which are Princess Nourah Bint Abdurrahman in Riyadh, which is the largest university for women in the world, female colleges at King Saud University in Riyadh, and female colleges of King Abulaziz University in Jeddah. To identify the nascent entrepreneurs, technology incubator, and entrepreneurship programs were targeted, including Badir's program from the scientific organization of King Abdulaziz City for Science and Technology, as well as King Salman Institute for Entrepreneurship program at King Saud University. The data were analysed using Partial Least Squares (PLS) Structural Equation Modelling (SEM) approach using the SmartPLS version 3 (Ringle et al. 2014). PLS allows the 
researchers for evaluating the model of structural coefficients and the measurement tools. In this study, the proposed model has both formative and reflective variables. All factors are considered as the reflective indicators, because they were considered as effects of latent variables. This is consistent with prior research, such as (Chen 2013; Chen 2014; Dutta et al. 2015; Liao and Welsch 2005). The exception to this is subjective norms, which is formative in nature because it is a multi-dimensional factor that covers various referent groups such as family, friends and colleagues, following the guidelines by Eckhardt et al. (2009) for social influence as a formative construct (Eckhardt et al. 2009).

\section{Conclusion and Expected Contribution}

This study aims to make a significant contribution by examining empirically women's IT entrepreneurial intention as well as the impact of IT based on the theory of planned behaviour. Based on previous literature, the model has been proposed to answer the research questions. By investigating the effects of such factors, this study is expected to contribute to the literature in several ways. First, it contributes to information systems and female entrepreneurship literature by enhancing our understanding of aspects influencing the decisions of women to create new business in the IT-related industries, where women are underrepresented. It explores how IT level could play a role in the formulation of entrepreneurial intention. Furthermore, this study is a reconfirmation of the theory of planned behavior in predicting the entrepreneurial intentions from developing countries context in general and Saudi women context in particular. The IT entrepreneurial intention model developed in this study can be a new driver of IT entrepreneurial behavior among women, which has rich practical implications for enhancing entrepreneurship, economic growth and innovation. Significantly, our study also contributes to support Kingdom's new economic direction that aims to increase SME contribution to the economy, increase women's participation in the workforce and transferring the economic system from its oil-based economy to a knowledge-based economy through innovation and technology.

The methodology used in this study, which is a quantitative method, would allow the researcher to obtain a greater generalization of the result to generalize the entire population of women in Saudi Arabia. However, the research results were not of universal applications and might not be fully generalizable to other developing countries since the research was conducted in a specific context. The results of this research might be generalized through further examination and testing in other countries. Finally, like any research this study has limitations. Although, as explained earlier, the election of intentional theory is justified by their acceptance and generalized use to explain entrepreneurial intentions in different contexts and areas, we confirm that entrepreneurial intention is not the actual behavior. Thus, this is an area for future research to consider the IT entrepreneurial behaviour as well.

\section{References}

Agarwal, R., and Prasad, J. 1998. "A Conceptual and Operational Definition of Personal Innovativeness in the Domain of Information Technology," Information systems research (9:2), pp. 204-215.

Ajzen, I. 1991. "The Theory of Planned Behavior," Organizational behavior and human decision processes (50:2), pp. 179-211.

Aleidi, A., and Chandran, D. 2017a. "Does Institutional Environment Promote Women's It Entrepreneurial Intention in Saudi Arabia? Technological and Institutional Perspectives," PACIS 2017 Proceedings. 208.).

Aleidi, A., and Chandran, D. 2017b. "Technological and Institutional Perspectives of Women's It Entrepreneurial Intention in Saudi Arabia,").

Aleidi, A., and Chandran, D. 2018. "Budding Female It Entrepreneurs in Saudi Arabia: Impact of It and Institutional Environment,").

Almobaireek, W. N., and Manolova, T. S. 2013. "Entrepreneurial Motivations among Female University Youth in Saudi Arabia," Journal of Business Economics and Management (14:sup1), pp. S56S75.

Anna, A. L., Chandler, G. N., Jansen, E., and Mero, N. P. 200o. "Women Business Owners in Traditional and Non-Traditional Industries," Journal of Business venturing (15:3), pp. 279-303.

Autio, E., H. Keeley, R., Klofsten, M., GC Parker, G., and Hay, M. 2001. "Entrepreneurial Intent among Students in Scandinavia and in the USA," Enterprise and Innovation Management Studies (2:2), pp. 145-160.

Bandura, A. 1986. Social Foundations of Thought and Action: A Social Cognitive Theory. Prentice-Hall, Inc.

Chandran, D., and Aleidi, A. 2018. "Analyzing the Influence of Gender Stereotypes and Social Norms on Female It Entrepreneurial Intention in Saudi Arabia," Proceedings of the 51st Hawaii International Conference on System Sciences. 
Chen, C. C., Greene, P. G., and Crick, A. 1998. "Does Entrepreneurial Self-Efficacy Distinguish Entrepreneurs from Managers?," Journal of business venturing (13:4), pp. 295-316.

Chen, L. 2013. "It Entrepreneurial Intention among College Students: An Empirical Study," Journal of Information Systems Education (24:3), p. 233.

Chen, L. 2014. "Understanding It Entrepreneurial Intention: An Information Systems View," Journal of Computer Information Systems (55:1), pp. 2-12.

Compeau, D. R., and Higgins, C. A. 1995. "Computer Self-Efficacy: Development of a Measure and Initial Test," MIS quarterly), pp. 189-211.

Díaz-García, M. C., and Jiménez-Moreno, J. 2010. "Entrepreneurial Intention: The Role of Gender," International Entrepreneurship and Management Journal (6:3), pp. 261-283.

Dutta, D. K., Gwebu, K. L., and Wang, J. 2015. "Personal Innovativeness in Technology, Related Knowledge and Experience, and Entrepreneurial Intentions in Emerging Technology Industries: A Process of Causation or Effectuation?," International Entrepreneurship and Management Journal (11:3), pp. 529-555.

Eckhardt, A., Laumer, S., and Weitzel, T. 2009. "Who Influences Whom? Analyzing Workplace Referents' Social Influence on It Adoption and Non-Adoption," Journal of Information Technology (24:1), pp. 11-24.

Ezzedeen, S. R., and Zikic, J. 2012. "Entrepreneurial Experiences of Women in Canadian High Technology," International Journal of Gender and Entrepreneurship (4:1), pp. 44-64.

Fichman, R. G., and Kemerer, C. F. 1997. "The Assimilation of Software Process Innovations: An Organizational Learning Perspective," Management Science (43:10), pp. 1345-1363.

Hampton, A., McGowan, P., and Cooper, S. 2011. "Developing Quality in Female High-Technology Entrepreneurs' Networks," International Journal of Entrepreneurial Behavior \& Research (17:6), pp. 588-606.

He, J., and Freeman, L. A. 2010. "Understanding the Formation of General Computer Self-Efficacy," Communications of the Association for Information Systems (26:1), p. 12.

Krueger, N. F., Reilly, M. D., and Carsrud, A. L. 2000. "Competing Models of Entrepreneurial Intentions," Journal of business venturing (15:5), pp. 411-432.

Langowitz, N., and Minniti, M. 2007. "The Entrepreneurial Propensity of Women," Entrepreneurship theory and practice (31:3).

Lenox, M., and King, A. 2004. "Prospects for Developing Absorptive Capacity through Internal Information Provision," Strategic Management Journal (25:4), pp. 331-345.

Liao, J., and Welsch, H. 2005. "Roles of Social Capital in Venture Creation: Key Dimensions and Research Implications," Journal of small business management (43:4), pp. 345-362.

Marlow, S., and McAdam, M. 2012. "Analyzing the Influence of Gender Upon High-Technology Venturing within the Context of Business Incubation," Entrepreneurship Theory and Practice (36:4), pp. 655-676.

Marvel, M. R., and Lumpkin, G. T. 2007. "Technology Entrepreneurs' Human Capital and Its Effects on Innovation Radicalness," Entrepreneurship Theory and Practice (31:6), pp. 807-828.

McGee, J. E., Peterson, M., Mueller, S. L., and Sequeira, J. M. 2009. "Entrepreneurial Self-Efficacy: Refining the Measure," Entrepreneurship theory and Practice (33:4), pp. 965-988.

Misk. 2018. "Misk." 2018, from https://misk.org.sa/fellowship/she-means-business/

Nichols, S. P., and Armstrong, N. E. 2003. "Engineering Entrepreneurship: Does Entrepreneurship Have a Role in Engineering Education?," Antennas and Propagation Magazine, IEEE (45:1), pp. 134-138.

Palmer, J., Griswold, M., Eidson, V., and Wiewel, P. 2015. "Entrepreneurial Intentions of Male and Female University Students," International Journal of Business \& Public Administration (12:1).

Ringle, C., Wende, S., and Becker, J. 2014. "Smartpls 3," in: Hamburg: SmartPLS.

Roomi, M. A., de la Vega, I., AlAshri, O., and Coduras Martínez, A. 2017. Global Entrepreneurship Monitor Saudi Arabia 2016/17.

Venkatesh, V. 2000. "Determinants of Perceived Ease of Use: Integrating Control, Intrinsic Motivation, and Emotion into the Technology Acceptance Model," Information systems research (11:4), pp. $342-365$.

Willie O, S., Helen O, A., Abiodun A, E., and Maruf, S. 2011. "Framework for Technological Entrepreneurship Development: Key Issues and Policy Directions," American Journal of Industrial and Business Management (2011).

Wilson, F., Kickul, J., and Marlino, D. 2007. "Gender, Entrepreneurial Self-Efficacy, and Entrepreneurial Career Intentions," Entrepreneurship theory and practice (31:3).

Zhao, H., Seibert, S. E., and Hills, G. E. 2005. "The Mediating Role of Self-Efficacy in the Development of Entrepreneurial Intentions," Journal of applied psychology (90:6), p. 1265. 